\title{
Grape seed proanthocyanidins induce mitochondrial pathway-mediated apoptosis in human colorectal carcinoma cells
}

\author{
CHEN ZHANG ${ }^{1,2}$, WEILI CHEN ${ }^{3}$, XUHAO ZHANG $^{4}$, YANBING ZHENG $^{3}$, \\ FENGLI YU ${ }^{3}$, YULONG LIU ${ }^{5}$ and YI WANG ${ }^{1}$ \\ ${ }^{1}$ Department of Regenerative Medicine, School of Pharmaceutical Sciences, Jilin University, \\ Changchun, Jilin 130021; ${ }^{2}$ Xiamen Institute of Rare Earth Materials, Haixi Institute, Chinese Academy of \\ Sciences, Xiamen, Fujian 361021; ${ }^{3}$ Department of Chemistry and Physics, Heihe University, Heihe, \\ Heilongjiang 164300; ${ }^{4}$ Institute of Translational Medicine, The First Hospital, Jilin University, Changchun, Jilin 130031; \\ ${ }^{5}$ State Key Laboratory of Supramolecular Structure and Materials, Jilin University, Changchun, Jilin 130012, P.R. China
}

Received December 8, 2015; Accepted August 17, 2017

DOI: $10.3892 / \mathrm{ol} .2017 .6992$

\begin{abstract}
Grape seed proanthocyanidins (GSPs) have been reported to possess a wide array of pharmacological and biochemical properties. Recently, GSPs have been reported to inhibit various types of colorectal cancer; however, the mechanism(s) involved remain unclear. The present study investigated the effects of GSPs on HCT-116 human colorectal carcinoma cell line. Exposure of these cells to GSPs for $48 \mathrm{~h}$ resulted in a significant concentration-dependent inhibition of cell viability. Further investigation indicated that GSPs induced apoptosis of these cells. Analyses of mRNA expression levels using reverse transcription-quantitative polymerase chain reaction and protein expression levels by western blotting revealed that this was associated with increased expression levels of $\mathrm{p} 53$ tumor suppressor protein, cytochrome $c$, and pro-apoptotic proteins, apoptosis regulator $\mathrm{Bax}(\mathrm{Bax})$ and $\mathrm{Bcl}-2$ homologous antagonist/killer. Furthermore, decreased expression levels of the anti-apoptotic protein, B cell lymphoma-2 and activation of caspase-2, caspase-3 and caspase- 9 were demonstrated. GSP-induced loss of mitochondrial membrane potential was also detected by JC-1 assay. These findings suggested that GSPs induced colon cancer cell apoptosis via the mitochondrial signaling pathway. This provided evidence indicating that GSPs may provide potential chemotherapeutic agents for colorectal cancer.
\end{abstract}

\section{Introduction}

Colorectal cancer (CRC) is a type of cancer that is most associated with dietary factors, and has the third highest mortality

Correspondence to: Professor Yi Wang, Department of Regenerative Medicine, School of Pharmaceutical Sciences, Jilin University, 1266 Fujin Road, Changchun, Jilin 130021, P.R. China E-mail: wangyi@jlu.edu.cn

Key words: apoptosis, B cell lymphoma-2 family, caspase family, grape seed proanthocyanidins, HCT-116, p53, cytochrome $c$ rate of common malignancies in males and females (1-3). Due to the continued urbanization of the population, the morbidity and mortality rates associated with CRC are increasing gradually worldwide. In addition to genetic factors, eating habits and environmental factors markedly influence the relative risk for the occurrence, and development of colon cancer $(4,5)$. Although CRC incidence rates have decreased to a certain degree, there is certain evidence indicating that current therapies are expensive and induce debilitating side effects; in addition, recurrence rates of $>50 \%$ have been reported, primarily due to the development of acquired chemoresistance to conventional chemotherapeutic regimens $(6,7)$.

Grape seeds are an effective source of proanthocyanidins (8). Grape seed proanthocyanidins (GSPs) are primarily composed of dimers, trimers and oligomers of monomeric anthocyanidin $(9,10)$. There are a number of biological functions of GSPs, including antimutagenic, anti-inflammatory, anti-angiogenic and anticarcinogenic activities (11-15). Previous studies have demonstrated that GSPs have cytotoxic effects in numerous cancer cell lines; however, the mechanisms underlying these anticancer effects remain uncharacterized (16-18).

Apoptosis, or programmed cell death, serves a key role in regulating the development and growth of normal cells, and is often dysregulated in cancer cells (19). p53, the tumor suppressor protein, serves an essential role in apoptosis and acts as a suppressor of transformation $(20,21)$, in addition, the expression level of p53 has been revealed to be induced by DNA damage (22). In turn, p53 orchestrates a global transcriptional response that counters cell proliferation or induces apoptosis (23-25). GSPs have been demonstrated to protect against stress-induced changes in the expression levels of p53 and the anti-apoptotic protein, B cell lymphoma-2 (Bcl-2), in human oral epithelial (26), and liver (27) cells. The Bcl-2 family of proteins consists of pro- and anti-apoptotic regulators of apoptosis. The established mode of action of each separate entity involves protecting or disrupting mitochondrial integrity, thereby activating, or inhibiting the release of downstream factors, including cytochrome $c$ from the mitochondrion; these stimulate apoptosis (28). The apoptosis regulator Bax (Bax) 
and Bcl-2 homologous antagonist/killer (Bak) genes encode apoptosis-promoting members of the Bcl-2 gene family. The $\mathrm{Bcl}-2$ protein is known to form heterodimers with the Bax protein in vivo and the molar ratio of Bcl-2 to Bax determines whether apoptosis is induced or inhibited in target tissues (29). The Bax protein, considered to be one of the primary targets of p53, controls cell death by its participation in the disruption of mitochondria and the subsequent release of cytochrome $c$ (30). Bak also regulates the release of cytochrome $c$. Cytochrome $c$ release, in turn, activates caspase-9 and -3 (31). Cleaved caspase- 3 is regarded as a proximate mediator of apoptosis, whereas caspase- 2 triggered Bax-Bak-dependent and -independent cell death in colon cancer cells treated with resveratrol (32). Caspase family proteins serve a key role in the downstream events involved in p53-mediated apoptosis (33). Clustering of the initiator caspases activates the effector caspases, which trigger apoptosis (34).

The present study investigated the molecular mechanisms underlying GSP-induced apoptosis in the HCT-116 colon cancer cell line. Exposure of these cells to various concentrations of GSPs resulted in profound changes in morphology, proliferation and apoptosis. The present study investigated the involvement of $\mathrm{p} 53$, cytochrome $c$, Bcl-2 family proteins and caspases in this process, and the results indicated that GSPs may provide a novel approach to the treatment of CRC.

\section{Materials and methods}

Cell lines and culture. The HCT-116 human CRC cell line (Type Culture Collection of the Chinese Academy of Sciences, Shanghai, China) was cultured with McCoy's 5A (Sigma-Aldrich; Merck KGaA, Darmstadt, Germany) supplemented with $10 \%$ (vol/vol) heat-inactivated fetal bovine serum (FBS; Gibco; Thermo Fisher Scientific, Inc., Waltham, MA, USA), 100 IU penicillin and $100 \mu \mathrm{g} / \mathrm{ml}$ streptomycin (Invitrogen; Thermo Fisher Scientific, Inc.) in a humidified incubator at $37^{\circ} \mathrm{C}$ in $5 \% \mathrm{CO}_{2}$. The HF-91 human fibroblast cell line (Type Culture Collection of the Chinese Academy of Sciences) was cultured in DEME/H (Sigma-Aldrich; Merck $\mathrm{KGaA}$ ) supplemented with $10 \%$ (vol/vol) heat-inactivated FBS (Gibco; Thermo Fisher Scientific, Inc.), 100 IU penicillin and $100 \mu \mathrm{g} / \mathrm{ml}$ streptomycin (Invitrogen; Thermo Fisher Scientific, Inc.) in a humidified incubator at $37^{\circ} \mathrm{C}$ in $5 \% \mathrm{CO}_{2} . \mathrm{HCT}-116$ and HF-91 cells were plated in 96-well cell culture plates at $5 \times 10^{3}$ cells/well, and incubated for $24 \mathrm{~h}$. Triplicate wells were then treated with GSPs at various concentrations $(25,50$ or $100 \mu \mathrm{g} / \mathrm{ml}), 25 \mu \mathrm{g} / \mathrm{ml}$ 5-fluorouracil (5-Fu) as a positive control or PBS as the negative solvent control for $48 \mathrm{~h}$ prior to the analyses described below.

Reagents and antibodies. GSPs were purchased from Sigma-Aldrich (Merck KGaA; 20315-25-7). The antibodies used for western blotting were as follows: Mouse anti-caspase-2 (sc-5292), mouse anti-caspase-3 (sc-7272), mouse anti-caspase-9 (sc-56073), mouse anti-Bcl-2 (sc-7382), mouse anti-Bax (sc-20067), mouse anti- $\beta$-actin (sc-47778), rabbit anti-Bak (sc-7873), rabbit anti-mouse IgG-horseradish peroxidase (HRP; sc-358914) and mouse anti-rabbit IgG-HRP (sc-2357). All antibodies were purchased from Santa Cruz Biotechnology, Inc. (Dallas, TX, USA).
Cell viability. HCT-116 and HF-91 cells were plated in 96-well cell culture plates at $5 \times 10^{3}$ cells/well and incubated for $24 \mathrm{~h}$ at $37^{\circ} \mathrm{C}$. Triplicate wells were then treated with GSPs at various concentrations $(25,50$ or $100 \mu \mathrm{g} / \mathrm{ml}), 25 \mu \mathrm{g} / \mathrm{ml} \mathrm{5-Fu}$ as a positive control or PBS as the negative solvent control. Cell viability was determined after $48 \mathrm{~h}$ by adding $10 \mu \mathrm{l}(5 \mathrm{mg} / \mathrm{ml})$ cell proliferation reagent (MTT; Sigma-Aldrich; Merck KGaA) and incubating for $24 \mathrm{~h}$ at $37^{\circ} \mathrm{C}$ until a purple precipitate was visible. The precipitate was then solubilized by adding dimethyl sulfoxide (Sigma-Aldrich; Merck KGaA). The absorbance was evaluated at $570 \mathrm{~nm}$ using a microplate reader. The percentage inhibition of cell viability was determined using the following formula: Percentage inhibition=1-optical density (OD) $)_{\text {treatment group }} / \mathrm{OD}_{\text {solvent control }} \times 100 \%$.

Annexin $V$ analysis. Annexin $\mathrm{V}$ and fluorescein isothiocyanate (FITC) staining was performed using a commercial Annexin V-FITC kit (BD Biosciences, Franklin Lakes, NJ, USA). Briefly, cells were treated with GSPs (25,50 or $100 \mu \mathrm{g} / \mathrm{ml}$ ), $25 \mu \mathrm{g} / \mathrm{ml} 5$-Fu as a positive control or PBS as a solvent control for $48 \mathrm{~h}$. The cells were then harvested, washed twice with cold PBS and resuspended in binding buffer at a concentration of $5 \times 10^{5}$ cells $/ \mathrm{ml}$. A $100-\mu 1$ aliquot containing $5 \times 10^{4}$ cells was incubated in the dark with $5 \mu \mathrm{l}$ Annexin V-FITC and $5 \mu \mathrm{l}$ propidium iodide (PI) at room temperature for $15 \mathrm{~min}$. Subsequently, $400 \mu 1$ binding buffer was added and the cells were viewed (5 fields for each group) using a fluorescence microscope (Olympus Corporation, Tokyo, Japan) at magnification x400. Viable cells were stained green and apoptotic cells were stained red. This experiment was repeated three times.

JC-1 assay. JC-1 analysis was performed using a commercial Mitochondrial Membrane Potential Detection JC-1 kit (BD Biosciences). Briefly, cells were treated with GSPs $(25,50$ or $100 \mu \mathrm{g} / \mathrm{ml}), 25 \mu \mathrm{g} / \mathrm{ml} \mathrm{5-Fu} \mathrm{as} \mathrm{a} \mathrm{positive} \mathrm{control} \mathrm{or} \mathrm{PBS} \mathrm{as} \mathrm{a}$ solvent control for $48 \mathrm{~h}$ prior to harvesting, washing twice with cold PBS and resuspending in binding buffer at a concentration of $1 \times 10^{6}$ cells $/ \mathrm{ml}$. A $100-\mu 1$ aliquot was incubated with $5 \mu \mathrm{l} \mathrm{JC}-1$ and $5 \mu \mathrm{l} \mathrm{PI}$ in the dark at room temperature for 15 min. Subsequently, $400 \mu \mathrm{l}$ binding buffer was added and the cells were analyzed using a flow cytometer (Beckman Coulter, Inc., Brea, CA, USA). Cells negative for JC-1 and PI were considered to be viable; JC-1+/PI+ cells were in early apoptosis; JC-1+/PI- cells were necrotic or in late apoptosis. This experiment was repeated three times.

Reverse transcription-quantitative polymerase chain reaction $(R T-q P C R)$. Total RNA was isolated from treated cells using TRIzol ${ }^{\circledR}$ reagent (Invitrogen; Thermo Fisher Scientific, Inc.). First-strand cDNA was reverse transcribed using the PrimeScript ${ }^{\mathrm{TM}}$ RT reagent kit (Takara Bio, Inc., Otsu, Japan), in accordance with the manufacturer's protocols. Relative expression levels of mRNA were determined by qPCR using the primer sequences presented in Table I and a Thermo ${ }^{\circledR}$ PikoReal 96 system (Thermo Fisher Scientific., Inc.). GAPDH was used as the endogenous reference gene. cDNA was subjected to $40 \mathrm{PCR}$ cycles of $94^{\circ} \mathrm{C}$ for $30 \mathrm{sec}, 60^{\circ} \mathrm{C}$ for $30 \mathrm{sec}$ and $72^{\circ} \mathrm{C}$ for $45 \mathrm{sec}$ using FastStart Universal SYBR Green Master (Roche Diagnostics, Basel, Switzerland). Experiments were performed in triplicate and data were analyzed using 
Table I. Quantitative polymerase chain reaction primer sequences.

\begin{tabular}{|c|c|}
\hline Gene & Primer sequence (5'-3') \\
\hline Bcl-2 & $\begin{array}{l}\text { Forward: CATGTGTGTGGAGAGCGTCAA } \\
\text { Reverse: GCCGGTTCAGGTACTCAGTCA }\end{array}$ \\
\hline Bax & $\begin{array}{l}\text { Forward: GATCCAGGATCGAGCAGA } \\
\text { Reverse: AAGTAGAAGAGGGCAACCAC }\end{array}$ \\
\hline Bak & $\begin{array}{l}\text { Forward: AGATAGATAGCAGTAGTGCCTCA } \\
\text { Reverse: ATTGCCAGTAGAAGCTCTCATGGTT }\end{array}$ \\
\hline Caspase-2 & $\begin{array}{l}\text { Forward: CAAGTTCCTGAGCCTGGACTACATT } \\
\text { Reverse: GACAGATTGCTTTCCTCCAACATT }\end{array}$ \\
\hline Caspase-3 & $\begin{array}{l}\text { Forward: CAGAACTGGACTGTGGCATTGAG } \\
\text { Reverse: GGATGAACCAGGAGCCATCCT }\end{array}$ \\
\hline Caspase-9 & $\begin{array}{l}\text { Forward: GCGAACTAACAGGCAAGCAGC } \\
\text { Reverse: CGACATCACCAAATCCTCCAGAAC }\end{array}$ \\
\hline Cytochrome $\mathrm{C}$ & $\begin{array}{l}\text { Forward: GGTCAACAAATCATAAAGATATTGG } \\
\text { Reverse:TAAACTTCAGGGTGACCAATAAATCA }\end{array}$ \\
\hline p53 & $\begin{array}{l}\text { Forward: GCGGACTAACAGGCAAGCAAC } \\
\text { Reverse: CTCGTTTATACTCCTCCAGAAC }\end{array}$ \\
\hline GAPDH & $\begin{array}{l}\text { Forward: CGGAGTCAACGGATTTGGTCGTAT } \\
\text { Reverse: AGCCTTCTCCATGGTTGGTGAAGAC }\end{array}$ \\
\hline
\end{tabular}

BCL-2, B cell lymphoma-2; Bak, Bcl-2 homologous antagonist/killer; Bax, apoptosis regulator Bax.

Pikoreal software version 2.1. The average cycle threshold (Cq) values of the target genes were normalized to GAPDH gene expression level as $2^{-\Delta \Delta \mathrm{Cq}}(35)$. Changes in expression levels were presented either as fold increases or as the ratio of the target gene expression in the treated cells to its expression level in the control cells.

Western blotting. Six proteins involved in apoptosis (caspase-2, caspase-3, caspase-9, Bcl-2, Bak and Bax) were analyzed by western blotting. HCT-116 cells were exposed to GSPs $(25,50$ or $100 \mu \mathrm{g} / \mathrm{ml})$ at a concentration of $5 \times 10^{5}$ cells/well for $48 \mathrm{~h}$ in 6 -well plates, harvested and lysed in RIPA buffer (Pierce; Thermo Fisher Scientific, Inc.). Following a 30-min incubation on ice, the cell lysate was centrifuged at $10,000 \mathrm{x} \mathrm{g}$ at $4^{\circ} \mathrm{C}$ for $5 \mathrm{~min}$ and the supernatants were stored at $-80^{\circ} \mathrm{C}$ until use. The protein concentrations were determined using the Bradford assay (Bio-Rad Laboratories, Inc., Hercules, CA, USA). Proteins $(30 \mu \mathrm{g})$ were separated by $12 \%$ SDS-PAGE, transferred to polyvinyl difluoride membranes (EMD Millipore, Billerica, MA, USA) and blocked using 5\% non-fat dry milk in Tris-buffered saline (TBS) for $2 \mathrm{~h}$ at room temperature. The membranes were then incubated with 1:1,000 dilutions of the aforementioned primary antibodies in TBS overnight at $4{ }^{\circ} \mathrm{C}$, washed three times with TBS-Tween-20 and incubated with 1:5,000 dilutions of the appropriate secondary antibodies conjugated with HRP in TBS for $1 \mathrm{~h}$ at room temperature. Membranes were washed three times in TBS-Tween-20 at room temperature. Protein bands were visualized on X-ray film using an enhanced chemiluminescence (GE Healthcare, Chicago, IL, USA) detection system. Western blotting bands were quantified using the Odyssey infrared imaging system version 1.2 (LI-COR Biosciences, Lincoln, NE, USA).
Statistical analysis. Data are presented as the mean \pm standard deviations and all analyses were performed using Origin8 version 8.1.10.86 SRO (Origin8 Technologies Ltd., London, UK). Statistical significance was evaluated using two-way analysis of variance and Tukey's post hoc test. $\mathrm{P}<0.05$ was considered to indicate a statistically significant difference.

\section{Results}

Effect of GSPs on HCT-116 cell viability and apoptosis. MTT assays of HCT-116 and HF-91 cells treated with GSPs (25, 50 or $100 \mu \mathrm{g} / \mathrm{ml}), 5-\mathrm{Fu}(25 \mu \mathrm{g} / \mathrm{ml})$ or solvent control indicated that GSPs reduced HCT-116 cell viability in a concentration-dependent manner, whereas the inhibition of GSPs in HF-91 cells was significantly lower compared with that in 5-Fu-treated cells ( $\mathrm{P}<0.01$; Fig. 1A). HCT-116 cells exposed to GSPs demonstrated cell shrinkage and membrane blebbing (Fig. 1B). Annexin V/PI double staining of the treated and untreated cells revealed GSP concentration-dependent formation of apoptotic bodies in HCT-116 cells (Fig. 2).

GSP-mediated effects on p53, caspases and the Bcl-2 family. In the present study, the expression levels of p53 and cytochrome $c$ increased in GSP-treated cells. Significant overexpression was observed in HCT-116 cells exposed to $100 \mu \mathrm{g} / \mathrm{ml} \mathrm{GSPs}$ compared with 5-Fu, but not in those treated with lower concentrations of GSPs or with PBS (negative control; Fig. 3).

Considering the significance of caspases to apoptosis, the present study determines the mRNA and protein expression levels of initiator caspases (caspase-2 and -9) and an effector caspase (caspase-3). Upregulation of the mRNAs encoding caspase-2, caspase-3 and caspase-9 were observed in HCT-116 


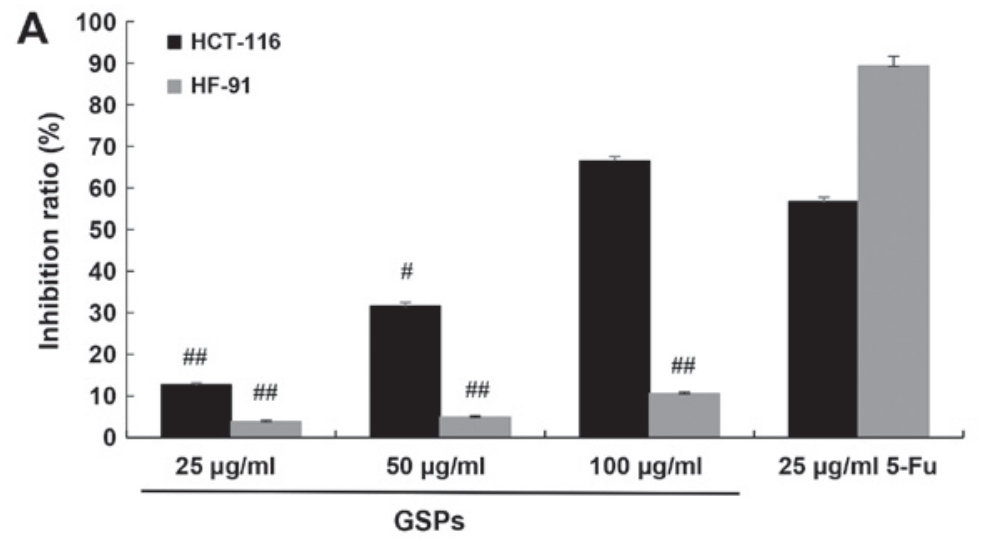

B

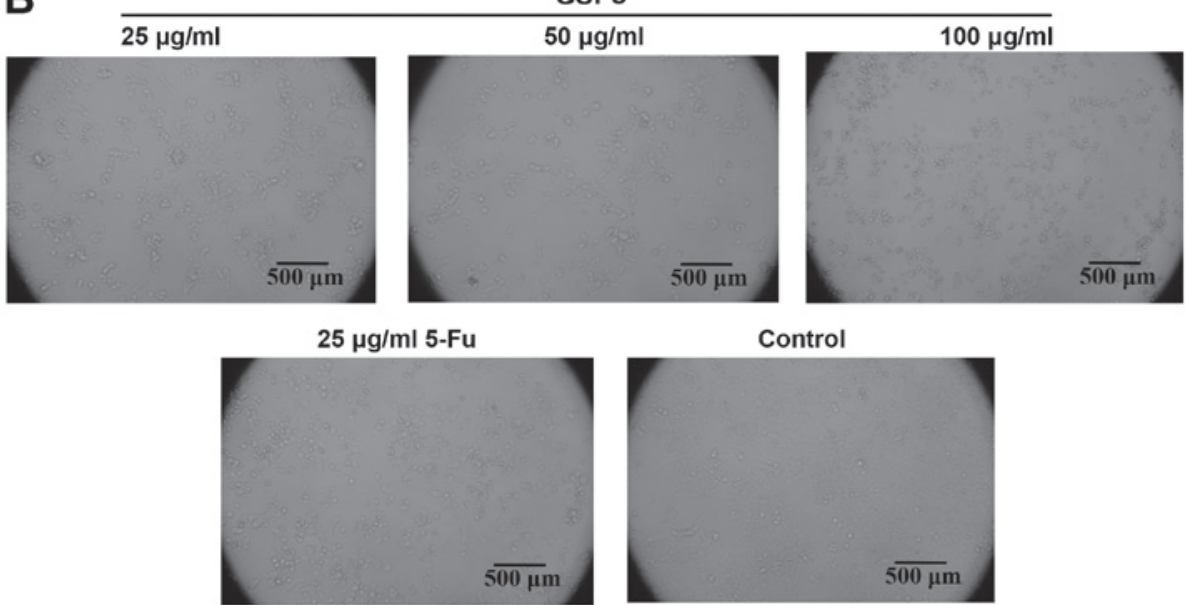

Figure 1. GSP-mediated antiproliferative effects in HCT-116 cells. (A) MTT assay was performed in HCT-116 and HF-91 cells following treatment with GSPs or 5-Fu. Data is presented as the mean \pm standard deviation of triplicate evaluations from one of three independent experiments. ${ }^{\prime \prime} \mathrm{P}<0.05$, for the comparison with 5-Fu-treated cells; ${ }^{\# \#} \mathrm{P}<0.01$, for the comparison with 5-Fu-treated cells. (B) HCT-116 cells revealed GSPs-induced cell shrinkage and membrane blebbing (scale bar, $500 \mu \mathrm{m}$ ). GSP, grape seed proanthocyanidins; 5-Fu, 5-fluorouracil.

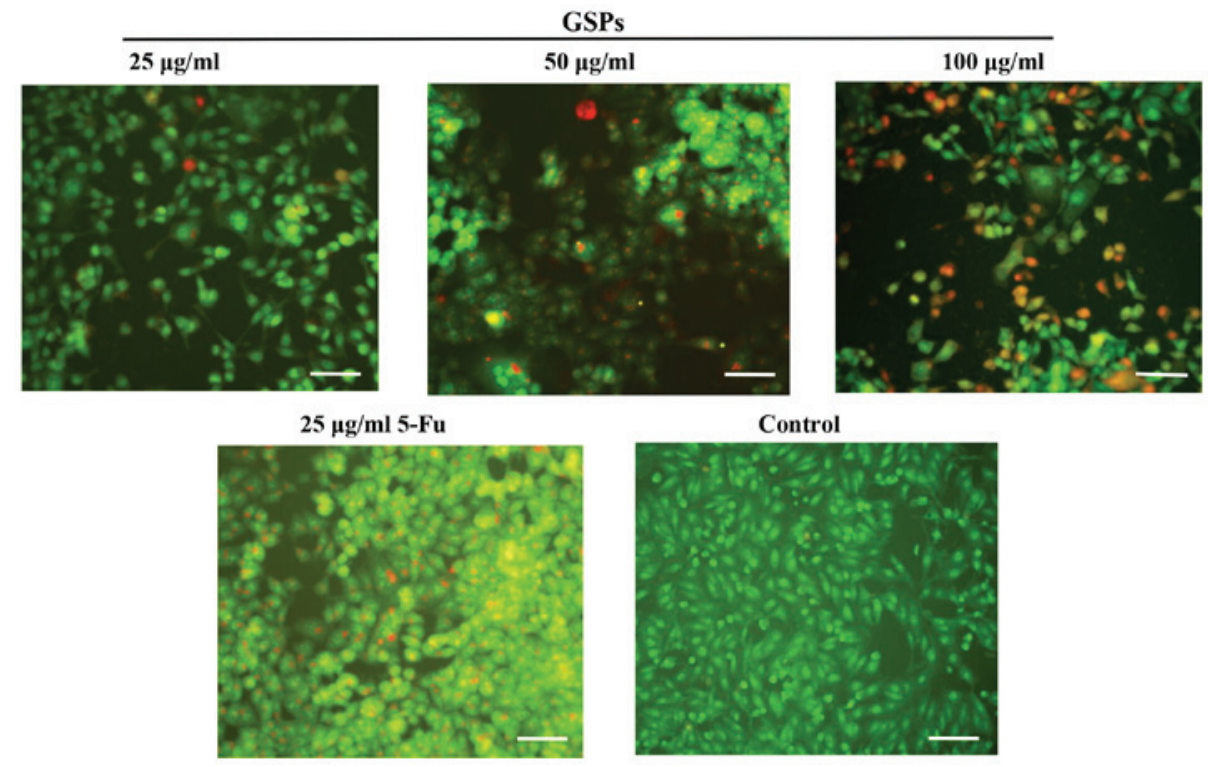

Figure 2. GSP-mediated induction of apoptosis in HCT-116 cells. Annexin V/propidium iodide staining analysis of HCT-116 cells were analyzed by flow cytometry following GSPs or 5-Fu treatment. Normal cells are presented in green and apoptotic cells are presented in red (scale bar, $500 \mu \mathrm{m}$ ). GSP, grape seed proanthocyanidins; 5-Fu, 5-fluorouracil.

cells exposed to GSPs for $48 \mathrm{~h}$ (Fig. 4A). Furthermore, the expression levels of cleaved caspase-2, caspase- 3 and caspase- 9 protein were also significantly increased in cells exposed to $100 \mu \mathrm{g} / \mathrm{ml} \mathrm{GSPs}$ compared with 5-Fu for $48 \mathrm{~h}$ (Fig. 4B and C). 

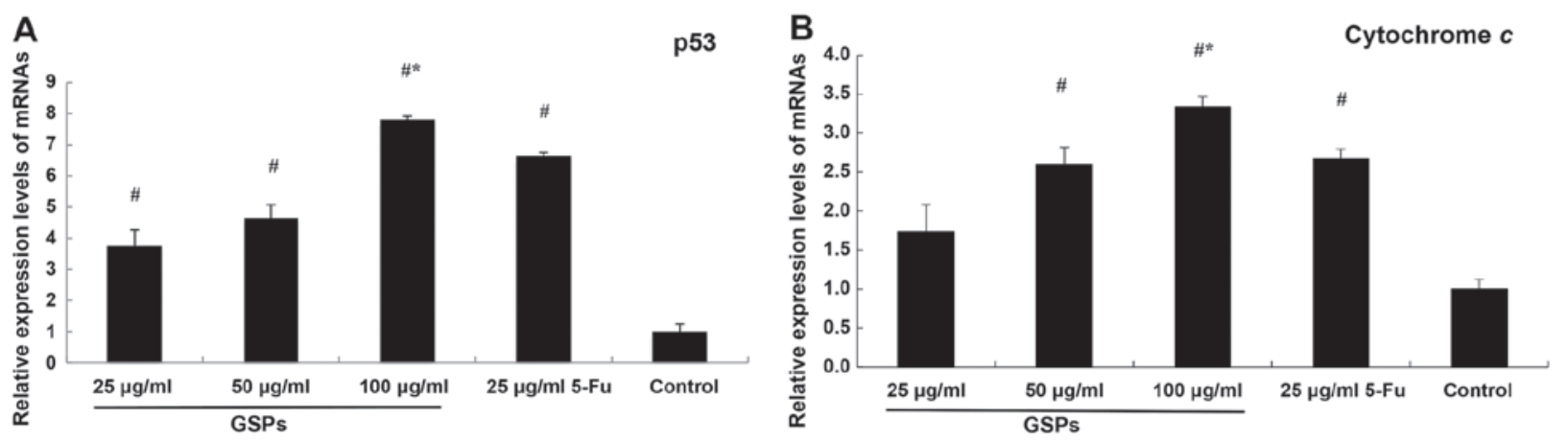

Figure 3. Effects of GSPs on mRNA expression levels of p53 and cytochrome C in HCT-116 cells. Quantitative-polymerase chain reaction analyses of (A) p53 and (B) cytochrome $c$ mRNA expression levels in HCT-116 cells exposed to GSPs or 5-Fu. Data is presented as the means \pm standard deviation of triplicate measurements from one of three independent experiments. " $\mathrm{P}<0.05$ for the comparison with control (PBS treated); ${ }^{*} \mathrm{P}<0.05$ for the comparison with 5-Fu-treated cells. GSP, grape seed proanthocyanidins; 5-Fu, 5-fluorouracil.

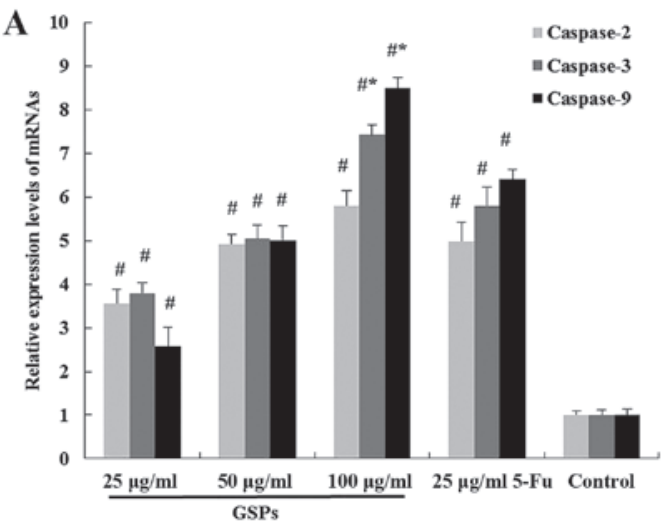

B
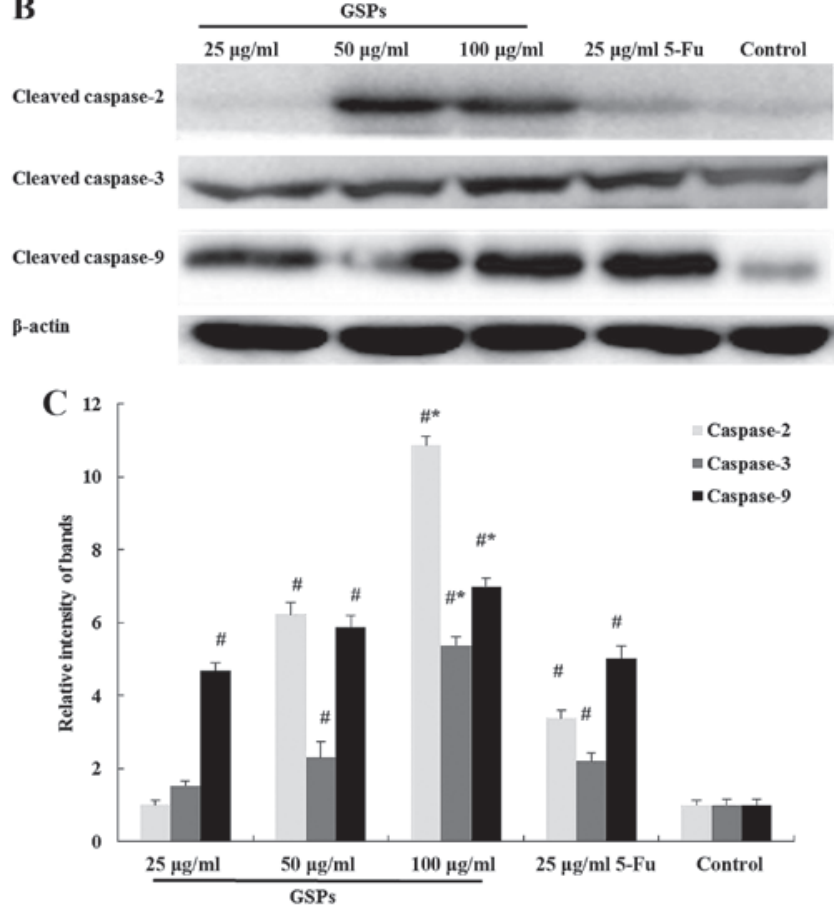

Figure 4. Effects of GSPs on the expression levels of caspase family in HCT-116 cells. (A) Quantitative-polymerase chain reaction analyses of caspase-2, caspase-3 and caspase-9 in HCT-116 cells exposed to GSPs or 5-Fu. (B) Western blot analysis of caspase-2, caspase-3 and caspase-9 in HCT-116 cells exposed to GSPs or 5-Fu. (C) Expression levels were normalized to $\beta$-actin and are relative to the control. ${ }^{~} \mathrm{P}<0.05$ for the comparison with control (PBS treated); ${ }^{\#} \mathrm{P}<0.05$ for the comparison with 5-Fu-treated cells. GSP, grape seed proanthocyanidins; 5-Fu, 5-fluorouracil.

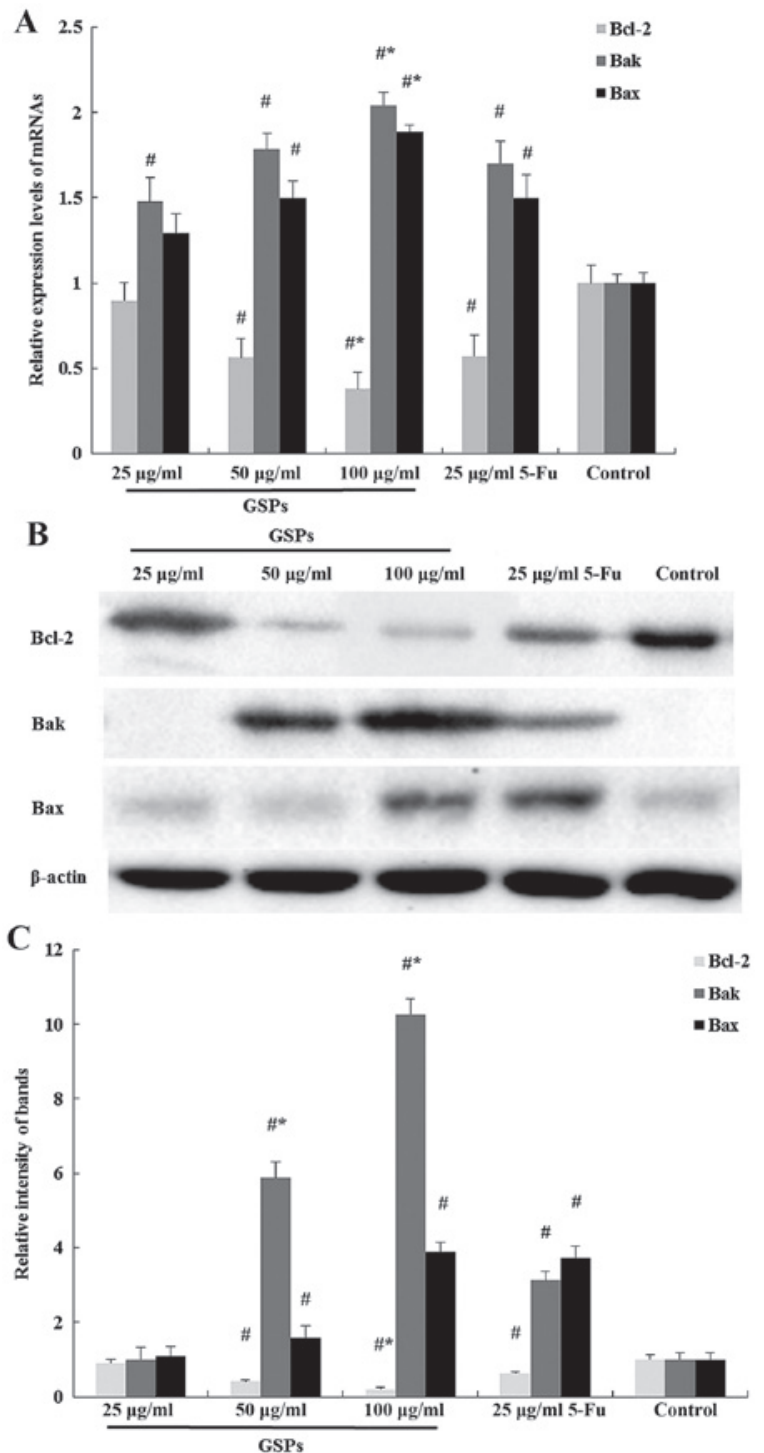

Figure 5. Effects of GSPs on the expression level of the Bcl-2 family in HCT-116 cells. (A) Quantitative-polymerase chain reaction analyses of Bcl-2, Bak and Bax in HCT-116 cells exposed to GSPs or 5-Fu. (B) Western blot analysis of Bcl-2, Bak and Bax in HCT-116 cells exposed to GSPs or 5-Fu. (C) Expression levels were normalized to $\beta$-actin and are relative to the control. ${ }^{\prime} \mathrm{P}<0.05$ for the comparison with control (PBS treated); ${ }^{*} \mathrm{P}<0.05$ for the comparison with 5-Fu-treated cells. GSP, grape seed proanthocyanidins; 5-Fu, 5-fluorouracil; Bcl-2, B cell lymphoma-2; Bak, Bcl-2 homologous antagonist/killer; Bax, apoptosis regulator Bax. 


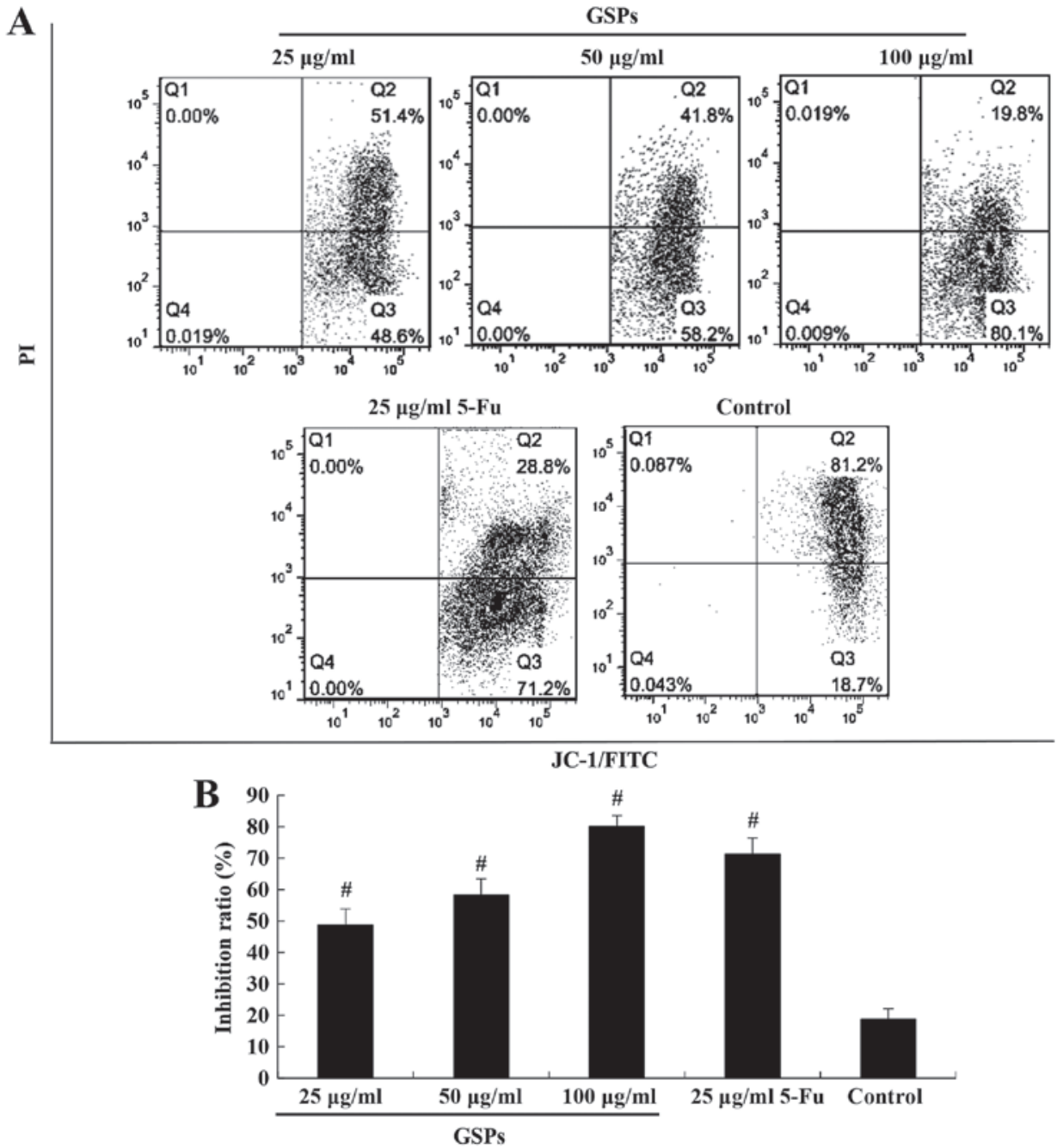

Figure 6. GSPs induce apoptosis in HCT-116 via the mitochondrial pathway. (A) JC-1 staining of HCT-116 cells exposed to GSPs or 5-Fu. Apoptotic cells are presented in the lower right quadrant of the dot plots. (B) Percentage of HCT-116 cells undergoing apoptosis following treatment with GSPs or 5-Fu, according to the JC-1 assay. Data is presented as the mean \pm standard deviation of triplicates from one of three independent experiments. "P $<0.05$ for the comparison with control; ${ }^{*} \mathrm{P}<0.05$ for the comparison with 5-Fu-treated cells. GSP, grape seed proanthocyanidins; 5-Fu, 5-fluorouracil; PI, propiduim iodide.

To further investigate the mechanism underlying GSP-induced apoptosis, the present study evaluated the mRNA and protein expression levels of Bcl-2, Bax and Bak by qPCR, and western blotting. The Bcl-2 expression level in $100 \mu \mathrm{g} / \mathrm{ml}$ GSPs group was significantly reduced compared with 5-Fu, whereas the expression levels of Bax and Bak were upregulated in HCT-116 cells exposed to GSPs for $48 \mathrm{~h}$ (Fig. 5A-C).

GSPs induce apoptosis via the mitochondrial pathway. Caspase-9 is involved in the mitochondrial apoptosis pathway and an increased expression level of cleaved caspase-9 therefore implied mitochondrial involvement in GSPs-induced apoptosis. JC-1 staining revealed that the percentage of cells with a loss of mitochondrial membrane potential increased from $18.7 \%$ in the negative control cells to $80.1 \%$ in the HCT-116 cells exposed to $100 \mu \mathrm{g} / \mathrm{ml} \mathrm{GSPs}$ (Fig. 6A). The percentage of apoptotic cells observed in Fig. 6A is summarized in Fig. 6B. This loss of mitochondrial membrane potential, coupled with the observed increase in cleaved caspase-9, suggested that GSPs induced HCT-116 cell death via the mitochondrial apoptosis pathway.

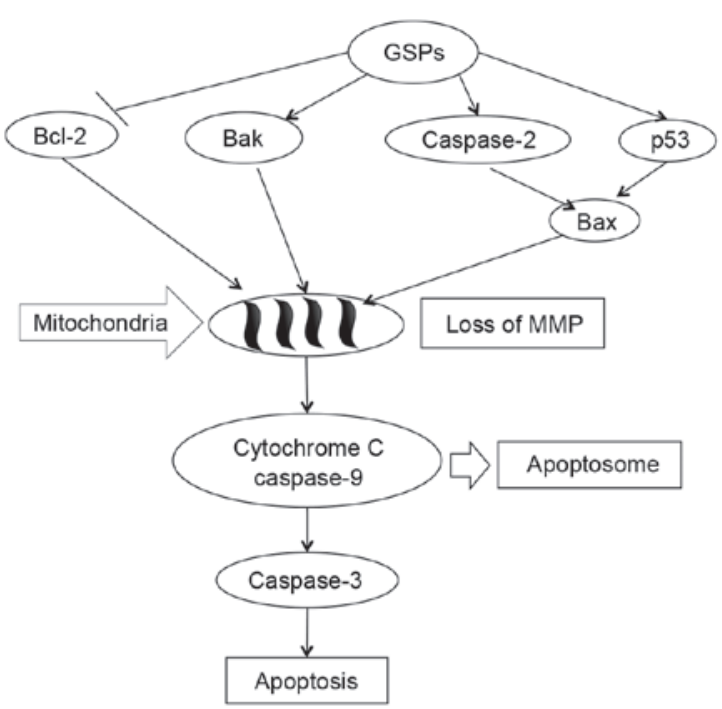

Figure 7. Mechanism diagram for the effects of GSPs in HCT-116 cells. GSPs modulate the expression and activation of numerous genes associated with the mitochondrial apoptotic pathway. GSP, grape seed proanthocyanidins; Bcl-2, B cell lymphoma-2; MMP, matrix metalloproteinase; Bak, Bcl-2 homologous antagonist/killer; Bax, apoptosis regulator Bax. 


\section{Discussion}

GSPs are observed in dietary botanical supplements and these compounds have been revealed to have anticarcinogenic properties (12-18,36). However, the molecular mechanisms underlying their effects in CRC are not clearly understood.

The cell proliferation inhibitory results in the present study regarding GSP treatment on the CRC cell line (HCT-116) are in agreement with the concentration-dependent effects reported for cyanidin on human colon cancer cell lines HCT-15 and HT-29 (37,38). However, GSPs revealed more active inhibition compared with cyanidin on colon cancer cells. This was accompanied by early and late apoptosis, and necrosis, observed using fluorescence microscopy and flow cytometry $(37,38)$. A series of experimental evidence suggested that GSPs are associated with the p53-induced mitochondrial apoptosis pathway, and involved with the Bcl-2 and caspase families (39). The Bcl-2 family consists of pro- and anti-apoptotic members that are associated with opposing effects on mitochondria. Bax and Bak regulate the release of cytochrome $c$, and the enhancement of cytochrome $c$ activates caspase-2,-3 and -9 (31,32). Caspase family proteins serve a key role in the regulation of p53-mediated apoptosis (33). Bax is a p53 target and a pro-apoptotic member of the Bcl-2 family of proteins $(40,41)$. Repression of anti-apoptotic members, including Bcl-2 and Bcl-xL, which are transcriptionally suppressed by p53 (42), preserves the integrity of the mitochondria. The present study demonstrated that GSPs upregulated the pro-apoptotic proteins (Bax and Bak) and caspase family proteins (caspase-2, -3 and -9), and downregulated the anti-apoptotic protein Bcl-2 in HCT-116 cells. It was observed that the increased expression level of $\mathrm{Bcl}-2$ induced the decrease of mitochondrial potential and eventually lead to apoptosis (43). The results of the present study revealed that GSPs mediated the reduction of the mitochondrial membrane potential in a concentration-dependent manner. Based on these results, Fig. 7 presents a schematic of the proposed molecular mechanisms underlying these effects of GSPs. Exposure to GSPs activated cleavage of caspase-2, caspase-3 and caspase-9 in HCT-116 cells, induced p53-mediated mitochondrial apoptosis signaling pathway with a concentration-dependent decrease in the expression level of the survival protein $\mathrm{Bcl}-2$, and increased the expression level of the pro-apoptotic proteins, Bax and Bak.

In conclusion, GSPs modulated the expression level and activation of numerous genes and proteins involved in the mitochondrial apoptotic pathway. These results proposed that GSPs prompted colon cancer cell apoptosis via the mitochondrial pathway and provided evidence demonstrating that GSPs may postulate potential chemotherapeutic agents for colorectal cancer.

\section{Acknowledgements}

The present study was supported by the Heilongjiang Province Science Foundation, China (grant no. H201380).

\section{References}

1. Jemal A, Center MM, Ward E and Thun MJ: Cancer occurrence. Methods Mol Biol 471: 3-29, 2009.

2. Jemal A, Bray F, Center MM, Ferlay J, Ward E and Forman D: Global cancer statistics. CA Cancer J Clin 61: 69-90, 2011.
3. Jemal A, Siegel R, Xu J and Ward E: Cancer statistics, 2010. CA Cancer J Clin 60: 277-300, 2010.

4. Markowitz SD and Bertagnolli MM: Molecular origins of cancer: Molecular basis of colorectal cancer. N Engl J Med 361: 2449-2460, 2009.

5. Wang X, Lu N, Yang Q, Gong D, Lin C, Zhang S, Xi M, Gao Y, Wei L, Guo Q and You Q: Studies on chemical modification and biology of a natural product, gambogic acid (III): Determination of the essential pharmacophore for biological activity. Eur J Med Chem 46: 1280-1290, 2011.

6. Zhang N, Yin Y, Xu SJ and Chen WS: 5-Fluorouracil: Mechanisms of resistance and reversal strategies. Molecules 13: 1551-1569, 2008.

7. Jiang WQ, Fu FF, Li YX, Wang WB, Wang HH, Jiang HP and Teng LS: Molecular biomarkers of colorectal cancer: Prognostic and predictive tools for clinical practice. J Zhejiang Univ Sci B 13: 663-675, 2012.

8. Mantena SK, Baliga MS and Katiyar SK: Grape seed proanthocyanidins induce apoptosis and inhibit metastasis of highly metastatic breast carcinoma cells. Carcinogenesis 27: 1682-1691, 2006.

9. Silva RC, Cheynier V and Chemina A: Procyanidin dimers and trimers from grape seeds. Phytochemistry 30: 1259-1264, 1991.

10. Prieur C, Rigaud J, Cheynier V and Moutounet M: Oligomeric and polymeric procyanidins from grape seeds. Phytochemistry 36: 781-789, 1994.

11. Vayalil PK, Mittal A and Katiyar SK: Proanthocyanidins from grape seeds inhibit expression of matrix metalloproteinases in human prostate carcinoma cells, which is associated with the inhibition of activation of MAPK and NF kappa B. Carcinogenesis 25: 987-995, 2004.

12. Singh RP, Tyagi AK, Dhanalakshmi S, Agarwal R and Agarwal C: Grape seed extract inhibits advanced human prostate tumor growth and angiogenesis and upregulates insulin-like grow th factor binding protein-3. Int J Cancer 108: 733-740, 2004.

13. Agarwal C, Singh RP, Dhanalakshmi S and Agarwal R: Anti-angiogenic efficacy of grape seed extract in endothelial cells. Oncol Rep 11: 681-685, 2004.

14. Mittal A, Elmets CA and Katiyar SK: Dietary feeding of proanthocyanidins from grape seeds prevents photocarcinogenesis in SKH-1 hairless mice: Relationship to decreased fat and lipid peroxidation. Carcinogenesis 24: 1379-1388, 2003.

15. Shi J, Yu J, Pohorly J and Kakuda Y: Polyphenolics in grape seeds-biochemistry and functionality. J Med Food 6: 291-299, 2003.

16. Bagchi D, Bagchi M, Stohs S, Ray SD, Sen CK and Preuss HG: Cellular protection with proanthocyanidins derived from grape seeds. Ann N Y Acad Sci 957: 260-270, 2002.

17. Tyagi A, Agarwal R and Agarwal C: Grape seed extract inhibits EGF-induced and constitutively active mitogenic signaling but activates JNK in human prostate carcinoma DU145 cells: Possible role in anti-proliferation and apoptosis. Oncogene 22: 1302-1316, 2003.

18. Sharma G, Tyagi AK, Singh RP, Chan DC and Agarwal R: Synergistic anti-cancer effects of grape seed extract and conventional cytotoxic agent doxorubicin against human breast carcinoma cells. Breast Cancer Res Treat 85: 1-12, 2004.

19. Wang LS and Stoner GD: Anthocyanins and their role in cancer prevention. Cancer Lett 269: 281-290, 2008.

20. Finlay CA, Hinds PW and Levine AJ: The p53 proto-oncogene can act as a suppressor of transformation. Cell 57: 1083-1093, 1989.

21. Karpinich NO, Tafani M, Rothman RJ, Russo MA and Farber JL: The course of etoposide induced apoptosis from damage to DNA and p53 activation to mitochondrial release of cytochrome c. J Biol Chem 277: 16547-16552, 2002.

22. Kastan MB, Onyekwere O, Sidransky D, Vogelstein B and Craig RW: Participation of p53 protein in the cellular response to DNA damage. Cancer Res 51: 6304-6311, 1991.

23. Sherr CJ: Principles of tumor suppression. Cell 116: 235-246, 2004.

24. Mercer WE, Shields MT, Amin M, Sauve GJ, Appella E, Romano JW and Ullrich SJ: Negative growth regulation in a glioblastoma tumor cell line that conditionally expresses human wild-type p53. Proc Natl Acad Sci USA 87: 6166-6170, 1990.

25. Baker SJ, Markowitz S, Fearon ER, Willson JK and Vogelstein B: Suppression of human colorectal carcinoma cell growth by wild-type p53. Science 249: 912-915, 1990.

26. Bagchi M, Kuszynski CA, Balmoori J, Joshi SS, Stohs SJ and Bagchi D: Protective effects of antioxidants against smokeless tobacco-induced oxidative stress and modulation of Bcl-2 and p53 genes in human oral keratinocytes. Free Radic Res 35: 181-194, 2001. 
27. Joshi SS, Kuszynski CA and Bagchi D: The cellular and molecular basis of health benefits of grape seed proanthocyanidin extract. Curr Pharm Biotechnol 2: 187-200, 2001.

28. Jia G, Wang Q, Wang R, Deng D, Xue L, Shao N, Zhang Y, $\mathrm{Xia} X$, Zhi F and Yang Y: Tubeimoside-1 induces glioma apoptosis through regulation of $\mathrm{Bax} / \mathrm{Bcl}-2$ and the ROS/Cytochrome C/Caspase-3 pathway. Onco Targets Ther 8: 303-311, 2015

29. Oltvai ZN, Milliman CL and Korsmeyer SJ: Bcl-2 heterodimerizes in vivo with a conserved homolog, Bax, that accelerates programmed cell death. Cell 74: 609-619, 1993.

30. Marzo I, Brenner C, Zamzami N, Jürgensmeier JM, Susin SA, Vieira HL, Prévost MC, Xie Z, Matsuyama S, Reed JC and Kroemer G: Bax and adenine nucleotide translocator cooperate in the mitochondrial control of apoptosis. Science 281: 2027-2031, 1998.

31. Wang X: The expanding role of mitochondria in apoptosis. Genes Dev 15: 2922-2933, 2001

32. Mohan J, Gandhi AA, Bhavya BC, Rashmi R, Karunagaran D, Indu $R$ and Santhoshkumar TR: Caspase-2 triggers Bax-Bak-dependent and -independent cell death in colon cancer cells treated with resveratrol. J Biol Chem 281: 17559-17611, 2006.

33. Tian Z, Shen J, Moseman AP, Yang Q, Yang J, Xiao P, $\mathrm{Wu} \mathrm{E}$ and Kohane IS: Dulxanthone A induces cell cycle arrest and apoptosis via up-regulation of $\mathrm{p} 53$ through mitochondrial pathway in HepG2 cells. Int J Cancer 122: 31-38, 2008.

34. Budihardjo I, Oliver H, Lutter M, Luo X and Wang X: Biochemical pathways of caspase activation during apoptosis. Annu Rev Cell Dev Biol 15: 269-290, 1999.

35. Livak KJ and Schmittgen TD: Analysis of relative gene expression data using real-time quantitative PCR and the 2(-Delta Delta C(T)) method. Methods 25: 402-408, 2001.
36. Zhao J, Wang J, Chen Y and Agarwal R: Anti-tumor-promoting activity of a polyphenolic fraction isolated from grape seeds in the mouse skin two-stage initiation-promotion protocol and identification of procyanidin B5-3'-gallate as the most effective antioxidant constituent. Carcinogenesis 20: 1737-1745, 1999.

37. Kamei H, Hashimoto Y, Koide T, Kojima T and Hasegawa M: Anti-tumor effect of methanol extracts from red and white wines. Cancer Biother Radiopharm 13: 447-452, 1998.

38. Kang SY, Seeram NP, Nair MG and Bourquin LD: Tart cherry anthocyanins inhibit tumor development in ApcMin mice and reduce proliferation of human colon cancer cells. Cancer Letts 194: 13-19, 2003.

39. Roy AM, Baliga MS, Elmets CA and Katiyar SK: Grape seed proanthocyanidins induce apoptosis through p53, Bax, and caspase 3 pathways. Neoplasia 7: 24-36, 2005.

40. McCurrach ME, Connor TM, Knudson CM, Korsmeyer SJ, and Lowe SW. Bax-deficiency promotes drug resistance and oncogenic transformation by attenuating p53-dependent apoptosis. Proc Natl Acad 94: 2345-2349, 1997.

41. Yin C, Knudson CM, Korsmeyer SJ and Van Dyke T: Bax suppresses tumorigenesis and stimulates apoptosis in vivo. Nature 385: 637-640, 1997.

42. Ryan KM, Phillips AC and Vousden KH: Regulation and function of the p53 tumor suppressor protein. Curr Opin Cell Biol 13: 332-337, 2001.

43. Shih PH, Yeh CT and Yen GC: Effects of anthocyanidin on the inhibition of proliferation and induction of apoptosis in human gastric adenocarcinoma cells. Food Chem Toxicol 43: 1557-1566, 2005 . 